\section{IDENTIFICATION OF CRUCIAL STEPS AND SKILLS IN HIGH-ACHIEVERS' SOLVING COMPLEX MATHEMATICAL PROBLEM WITHIN MATHEMATICAL CONTEST}

\begin{abstract}
The aspects of inquiry based learning (IBL) are vigorously and frequently in the focus of recent studies. With the use of inquiry in mathematics in the daily school practice, some further questions are arising there: What kind of problems can be useful for an analysis of students' competencies in the field of IBL and how to assess the performed level of competencies? In this paper, the Mathematics B-day contest assignment is introduced as a mean to assess the students' performance in mathematical inquiry skills. Some new rubrics with didactical variables were designed as a tool for assessing students' competencies. The statistical implicative analysis was used to investigate 29 solutions of Mathematics B-day 2017: Arrow clocks. We identified the key subtasks solutions directly related to the level of the IBL competencies performed in the final mathematical investigation. The subtask which required actually high level of algebraic thinking influenced the level of the final mathematical investigation the most.
\end{abstract}

\section{KEYWORDS}

Assessment, competencies, inquiry based learning, mathematics education, open-ended problems

\section{HOW TO CITE}

Bulková K., Medová J., Čeretková S. (2020) 'Identification of Crucial Steps and Skills in High-Achievers' Solving Complex Mathematical Problem within Mathematical Contest', Journal on Efficiency and Responsibility in Education and Science, vol. 13, no. 2, pp. 67-78. http://dx.doi.org/10.7160/eriesj.2020.130202

\section{Kristína Bulková \\ Janka Medová \\ Soňa Čeretková}

Department of Mahtematics, Faculty

of Natural Sciences, Constantine

the Philosopher University in Nitra,

Slovakia

jmedova@ukf.sk

\section{Article history}

Received

November 19, 2020

Received in revised form

March 4, 2020

Accepted

April 29, 2020

Available on-line

June 30, 2020

\title{
Highlights
}

- Problem aiming at algebraic generalization was identified as having the highest influence and impact on the process of the solution of the open-ended mathematical problem.

- Aspects of creativity were interrelated between the partial problems.

- Creativity manifested in the solution of partial problems influenced the IBL competencies manifested in solution of the open-ended mathematical problem.

\section{INTRODUCTION}

The concept of Inquiry Based Learning (IBL) is based on the processes resting in posing, exploring and evaluating Yackel and Rasmussen (2002) define how to developing personally meaningful solutions, explaining students' approaches, ability to listen to each other and attempt to make sense of the thinking of other students as the characteristics of IBL. However, there is a necessity of teaching and learning with an understanding of what is essential for profound success in mathematics. Teaching and learning with an understanding requires a different approach of both involved parties, as the teachers, as the learners (Gonda and Tirpáková, 2018). Mathematical open-ended problems, which are close to the real situations, could represent a tool for the actual IBL implementation, and solutions there will require some specific multiple problem solving strategies. The term openended refers to an outcome of the work and to it whether more than one solution, design or answer is/are possible (Lock, 1990). On the other hand, contrary to the standard mathematical tasks, a solution of open-ended problems involves 'understanding the task, formulating an appropriate sequence of actions or strategy, applying the strategy to 
produce a solution, and then reflecting on the solution to ensure that it produced an appropriate response' (Blaško, 2013: 126) and offer to students an opportunity to inquire in the field of mathematics. Thus and then the students have an opportunity to learn on the basis of their own developed abilities, their levels of mathematical thinking, and gradually, self-develop them further (Nohda, 2000).

In case of mathematical inquiry problems, not only the correctness of a referred result is assessed, but also an approach and the steps of such approach used to solve the given problem are in the focus of the assessment (Samková, 2018). Nohda (2000) describes several criteria that could lead to the assessment: (a) how many different solutions were found, (b) what different ideas were found and investigated, (c) to what extent is the referred solution of the problem original, and (d) whether the thinking mode is elegant.

The students' solution should be provided in the written form, not only reporting results but also a process of the solution with a scale of sufficient reasoning. The written report represents a complex summary and description of mathematical results and thinking processes in an individual or in a team work (Russek, 1998). It is necessary to include any original data, tables and graphs, performing an analysis of data and their interpretation based on a related mathematical model. The ability to create the mentioned report as a mathematical writing is defined in the report. The written report also displays creativity as a product in sense of Leikin and Pitta-Pantazi (2013). Sternberg (1998) defines creativity as an ability to produce an original, appropriate and useful piece of work.

Authors' department is an organizer of the Mathematics B-day contest for Slovakia. The origin of this contest comes from the Netherlands where their Mathematics B-day contest is based on the educational program of mathematics for the university level applied in technical studies, as well as studies in the field of science and mathematics. Students solve specific assignment created with the intent to motivate inquiry practice in mathematics. Participants are encouraged to "use mathematical argumentation as much as possible" (Arrow clocks, 2017, p. 2), which implies the results in the form of mathematical expression and calls for a sufficient level of generalisation. Such assignment comprises of about 15 to 20 pages of mathematical text divided into the basic and final assignments. Teams consist of three or four students who are working on a written final report by conjecturing and proving in mathematics, demonstrating their mathematical knowledge and competences (Utrecht University, 2018). 'The preparing for the competition, and trying to solve the problems during the competition itself, all participants increase their knowledge significantly, also the teacher gains an experience how to teach mathematical topics that are currently not in the curriculum' (Kenderov, 2006: 1589). Students are challenged to showing their own process skills in developing certain new strategies, making conjectures, trying to prove or reject these (Maaß and Reitz-Koncebovski, 2013). Through this process and awaited way, students are required to work as mathematicians, and just for it, this is one of the core characteristics of the IBL (Maaß and Artique, 2013).

Recent studies focus on the implementation of IBL into the current educational process (Engeln Euler and Maass, 2013; Bruder and Prescott, 2013). Therefore, Mathematics B-day contest provides students with a unique opportunity to participate in inquiring mathematical principles. The goal of this paper is to verify whether the complex assignment, like our Mathematical B-day aims to be, is a reasonable instrument to estimate an actual level of students' performance in the process of mathematical problem-solving. In comparison with the preliminary analysis (Medová, Bulková and Čeretková (2018), the current paper focus more on the process of assessing the students' solutions and presents the excerpts of their work. The following two research questions were formulated there:

What types of (implicative) relations do exist there between the levels achieved in the field of chosen attributes and manifested competencies?

Which subtasks of the basic assignment had a significant importance for the performance in the final assignment, particularly, in sense of manifested IBL competencies?

\section{MATERIALS AND METHODS}

\section{Participants}

The Mathematics B-day contest is aimed at the upper secondary students devoted and interested in mathematics. For the contest assessment as such only two best reports from each school are submitted, therefore a relatively high achievement in solving process and in creating the mathematical model can be anticipated. The actual ability to solve non-routine mathematical problems is definitely one among the basic components of the general problemsolving ability (Pantziara, Gagatsis and Elia, 2009). The non-routine problems always demand a high cognitive load (Schoenfeld, 1992), so the high-achievers' solutions need to be analysed. For this reason, the solvers, who participated in our Mathematical B-day, represent an appropriate sample for observing the level of different competencies related to the mathematical inquiry.

\section{Assignment specification}

In the assignment of Mathematics B-day 2017 the Arrow clocks, a number theory, was chosen as the main area for working with the divisibility of numbers and residual classes through modular arithmetic (Duriš and Lengyelfalusy, 2019). Whereas modular arithmetic is not usually a part of the Slovak mathematics curriculum the assignment can be considered as a series of novel problems for all the participating teams of students. As far as to other areas of mathematics, there was required a wider knowledge in the field of functions, projection in geometry, mapping the points based on the general rule $x \rightarrow$ $a x+b$, etc. The whole assignment as such is designed in such a way that our students can move smoothly from some concrete results to some generalized conclusions, and then they can gain a new experience in the field of higher mathematics as a result. Thus, the basic assignment consisted of the eight main parts (with the subtasks marked with a letter, e.g. as 1a, etc.). The initial problem as a rule introduced the principle of the arrow clocks, as well as the way, how it can be represented by a simple prescription (Figure 1). 


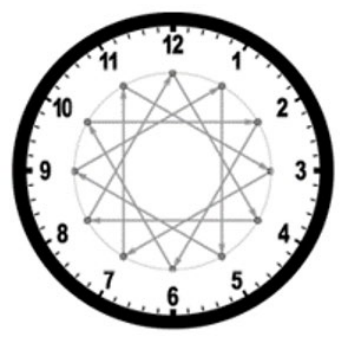

(A)

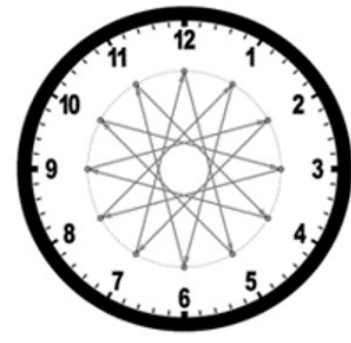

(B)

Figure 1: Examples of Arrow clocks $x \rightarrow x+9$ (A) and $x \rightarrow x+5$ (B), $x \in\{1,2, \ldots, 12\}$ (Arrow clocks, 2017)

Based on the introductory tasks, the students were exploring how the ornament is changing, observing new shapes based on the changing rule of arrow clocks. Their findings were aimed at several cases. Some ornaments of the arrow clocks were composed of regular triangles or quadrilaterals (Figure $1 \mathrm{~A}$ ), and in some other cases, the shape represents one stroke which connects all dial faces (Figure $1 \mathrm{~B}$ ).

The following problems were guiding an exploration of the properties of different types of clocks with different rules. The whole assignment is written with an intention to aim their exploration at the greatest common divisor of $b$ (from the general rule $x \rightarrow a x+b$ ) and the number of points on the dial. For the sake of simplification as well as for unifying in the written report of the solution, the relation of congruency modulo $n$ was explained to students by the simple visualisation (Figure 2).

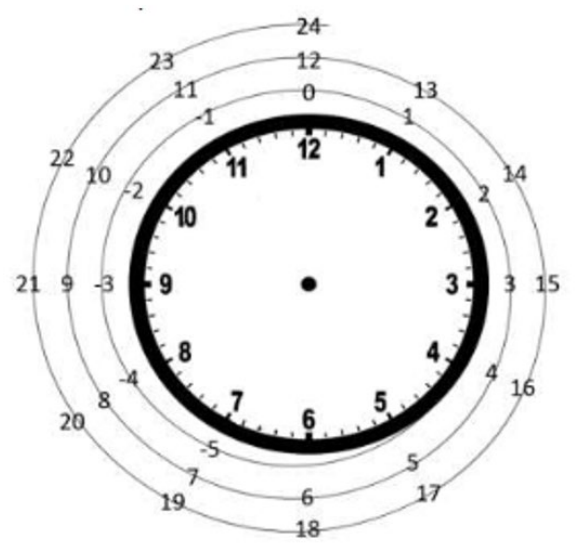

Figure 2: Model explaining the congruence modulo (source: Arrow clock, 2017)

Thus, the chosen knowledge coming from the number theory is followed by problems where the participating students can discover certain properties of various arrow clock patterns, and then, they are proving their validity in general. Indeed, the solved problems featured an increasing difficulty. For example, the standard clock face is divided into the 15,17 or 45 parts, and later on, the variable $n$ is used instead.

Gradually, by the generalization of previous explorations about modular arithmetic, by proving the conjectures and solutions and using the dynamic mathematics software GeoGebra for experiments, our students are encouraged to connect all their findings into a mathematical model. In the final assignment, students performed their own original research. They were challenged for the following subtasks: 'Describe what geometrical phenomenon you are seeing: think of the mutual placement of the lines or arrows, rotational or axial symmetry... Find patterns.... Explain the patterns.' (Arrow clocks, 2017: 14).

\section{Rubrics}

The assessment of the mathematical open-ended problem or mathematical inquiry problem is not uniform at all (Dorier,
2012). The correctness of results indicates some higher students' competencies, but also the steps of the solution process are in the focus of the assessing process. Several recent studies have been looking for an objective tool for assessing mathematical inquiry problems. Rubrics can be helpful to minimize subjective views in assessing the solutions of mathematical open-ended problems. To judge the quality of a broad range of subjects, the use of rubrics is a guide to the evaluation of the written work of students (Moskal, 2000).

Brookhart (2013: 5) defines rubrics as 'a coherent set of criteria that includes descriptions of levels of performance quality on the criteria'. To creating any rubric, it is necessary to define certain criteria specific for the assessed attribute and to specify the count of levels. The rubric is complete when the all levels of performance are described there. The purpose lies in the description of the level of the specific performance, while the assessor can select as many levels as it is necessary to describe in meaningful differences in performance quality.

The rubrics being used there to assessing the students' solutions had six levels based on the Bloom Taxonomy of Educational Objectives (Bloom et al., 1956). Each of these six levels defined in Revised Bloom Taxonomy of Educational Objectives can 
be characterised by an active verb (Anderson and Krathwohl, 2001). In the case of mathematical inquiry, always students operate with their mathematical competencies, which are manifested in the solution as such. Therefore, any simple suitable assessing tool may be based on the analysis of students' mathematical competencies in the field of mathematical modelling skills as the highest level of mathematical thinking within the IBL structure. Mathematical modelling as such presents the highest level of mathematical thinking based on the IBL structure. Thus, while using and applying rubrics it is also possible to observe the development of the IBL aspects as such. Any coherent set of criteria is described by the IBL processes associated to the appropriate level vested in Bloom Taxonomy of Educational, see Table 1.

\begin{tabular}{cllll} 
Level & \multicolumn{1}{c}{ Mathematical Competencies } & \multicolumn{1}{c}{ Processes of Inquiry Based Learning } & \multicolumn{1}{c}{ Active Verb } \\
1 & Usage of tools and information processing. & $\begin{array}{l}\text { Sorting information. } \\
\text { Observing systematically and visualising. }\end{array}$ & Remembering \\
\hline 2 & $\begin{array}{l}\text { Knowledge of concepts, facts, assertions and approaches. } \\
\text { Application of symbolic, formal and technical operations. }\end{array}$ & $\begin{array}{l}\text { Measuring and quantifying. } \\
\text { Controlling variables. }\end{array}$ & Understanding \\
\hline 3 & Description of mathematical objects and situations. & $\begin{array}{l}\text { Discovering connections and relationships. } \\
\text { Simplifying and structuring. }\end{array}$ & Applying \\
\hline 4 & $\begin{array}{l}\text { Defining the problem by asking a question. } \\
\text { Mathematical thinking and reasoning. }\end{array}$ & $\begin{array}{l}\text { Classifying and creating definitions. } \\
\text { Hypothesizing and predicting. }\end{array}$ & Analysing \\
\hline 5 & Mathematical arguments and proofs. & $\begin{array}{l}\text { Experimenting. } \\
\text { Inferring. }\end{array}$ & Evaluating \\
\hline 6 & Mathematical modelling. & Mathematical modelling. & Creating \\
\hline
\end{tabular}

Table 1: Rubrics of mathematical competencies and IBL processes (source: Bulková, Čeretková, 2017a)

There is a possibility to create specific assessing tools relevant to other observed attributes. Mathematical writing can be used as an illustration of students' reasoning of a problem or concept (Kosko and Wilkins, 2010). For mathematical writing as such, there was created a set of rubrics for the three monitored attributes (see Table 2). The principle of integrity of any mathematical text is based on the fluency of text and the continuity of sections. Under the term mathematical reasoning the proper formulation of sentences and the usage of mathematical argumentation required in order to create a mathematical text is understood. As a rule, there should be expected the proper and logic use of the standard mathematical terminology as well as terminology established by students. The criteria of clarity and readability are always closely related to the previous criteria, i.e. mathematical reasoning and integrity of mathematical text. Therefore, any text has to be clear, without any errors interfering with meaning (Bulková, Čeretková, 2017b).

The criteria for assessing creativity according to Zak (2004) are defined consistently and thoroughly (see Table 3 ). The criterion of originality assesses whether there are developed any original ideas and conclusions through the way of connecting, developing and conditioning of existing information. The criterion covering correctness of conclusion describes the meaningfulness and coherence of the final conclusion depending on the choice of relevant pieces of information as well as on correctness of the defining concepts, creating proper equations, reasoning assumptions etc. Developed ideas are not necessarily applicable for particular problem, eventually for its generalisation. The criterion lies on the following three rules: (a) any idea as such is not wrong by itself, (b) it has to be tried, and (c) the immediate inferences do not have to be correct (Bulková, Čeretková, 2017c).

All the above defined rubrics can be helpful to minimize subjective views in assessing solutions of mathematical inquiry problems. To explore respective mutual relations between the defined attributes of assessing, the implicative analysis was applied.

\section{Statistical analysis}

The statistical analysis of the obtained data was performed within the software environment $\mathrm{R}$ (R Core Team, 2018), package RVAideMemoire. The successrates in the subtasks of the assignment were compared by the Cochran $\mathrm{Q}$ test which is the generalisation of the McNemar test for two independent samples. The subtasks were considered as independent samples. Subsequently, the post-hoc analysis, comparing each pair of problems, was performed by the McNemar test. The level of studied variables in the final assignment according to the correct solution of chosen subtasks was compared by the Mann-Whitney's U test.

Following, the statistical implicative analysis (Gras et al, 1996) was performed using the software $\mathrm{CHIC}$ : cohesive hierarchical implicative classification ver. 3.3 (Couturier, 2008) and it was applied to explore respective mutual relations between the defined attributes of assessing and to evaluate relations between the subtasks in basic assignment and the students' performance in the final assignment (Table 4).

Then, two kinds of didactical variables were defined for all the subtasks; the correctness (Cor) of an answer for each particular subtask and the level of the observed property according to the above described rubrics (Table 5). Each of the "rubric" variables ending with a number according to level, e.g. MWrit_Intg_3 means that integrity of mathematical text reached the level 3 . We take into account that the correctness of the given subtask is an observable fact and the variables based on these rubrics are theoretical constructs, but in agreement with Nesher, Hershkovitz, and Novotna (2003) we assume that an analysis of both types of variables can facilitate a deeper understanding of the all aspects needed for a correct solution of the complex problem. 
The text does not meet the specific criteria

1 for the coherent mathematical text. The used information is irrelevant.

The text does not have a form of final report. The details are mostly relevant, but

2 information may be straggly and inaccurate. Pictures and tables do not support the comprehensibility of final report.

The text is composed of more independent reports.

3 Pictures and tables used in the report are not signed, described and arranged properly.

The text is composed of more dependent reports.

4 Lacking details interfere with the coherence of text.

The text has the form of the coherent mathematical text. Lacking details partly interfere with the coherence of text. Tables and pictures used in report are disarranged.

The text has a form of the coherent mathematical text. Information is relevant and exact. Pictures and tables used in the report are arranged and signed properly.
The final report is composed from

assumptions and reflections. It represents a sequence of unrelated materials. The mathematical terminology in text is not used.

The final report is not supported by any relevant facts. The basic mathematical terminology and argumentation is used.

The final report contains the occasional mathematical argumentation, but there is a lack of mathematical reasoning within the solution.

The final report contains the mathematical argumentation needed for processing the mathematical text.

The reasoning used resembles the form of mathematical proof

The final report contains mathematical evidence supported by mathematical argumentation.

Lacking connections between assignments were not explained.

The final report represents a coherent and organised mathematical text.

The mathematical argumentation and mathematical proofs are fully used in the text.
The text is not clear, the language style and word choice are not appropriate. Readers not familiar with the given assignment can be unable to understand the text.

The text is not entirely clear. The language style and word choice are simple. Readers not familiar with the assignment can be able to approximately determine the topic of solved problem.

The text is partly clear. The language style and word choice are simple.

Readers not familiar with can be able to determine the topic of solved problem.

The text is mostly clear. The language style and word choice are mostly effective. Readers not familiar with the assignment are able to define the point of solved problem.

The text is clear. Few errors do not interfere with meaning. Readers not familiar with the assignment are able to understand the solved problem.

The text is clear without any errors interfering with meaning. Readers not familiar with the assignment are able to understand the solved problem

Table 2: Set of rubrics to assess mathematical writing (source: Bulková, Čeretková, 2017b)

\begin{tabular}{|c|c|c|c|}
\hline Level & Aspects of Originality & The Correctness of Conclusions & $\begin{array}{l}\text { The Applicability of Conclusions and Solving } \\
\text { Processes for Consecutive Investigations }\end{array}$ \\
\hline 1 & $\begin{array}{l}\text { All ideas are copied from the assignment } \\
\text { and are created by rewording of that } \\
\text { assignment. }\end{array}$ & $\begin{array}{l}\text { The solution is not correct. Some } \\
\text { information is not exact. Ideas are based on } \\
\text { the false hypotheses. }\end{array}$ & $\begin{array}{l}\text { The conclusions do not represent a tool } \\
\text { for solving the problem, even for other } \\
\text { purposes. }\end{array}$ \\
\hline 2 & $\begin{array}{l}\text { Ideas are chosen from the field of main } \\
\text { topic. The conclusion is created by } \\
\text { rewording the assignment or on the basic } \\
\text { definitions of an expected result in order to } \\
\text { fit it to. }\end{array}$ & $\begin{array}{l}\text { The solution is not coherent. The used } \\
\text { information is not cohesive and not clear. }\end{array}$ & $\begin{array}{l}\text { The conclusions contain some elements for } \\
\text { solving some particular partial problems, but } \\
\text { not the problem as a whole. Ideas for solving } \\
\text { the concrete problem or situation are useful. }\end{array}$ \\
\hline 3 & $\begin{array}{l}\text { Ideas are connected to the related } \\
\text { mathematical field and to the basic } \\
\text { assumptions. }\end{array}$ & $\begin{array}{l}\text { The solution can be unclear in some parts, } \\
\text { mostly because of the missing details or } \\
\text { because of partially irrelevant information. }\end{array}$ & $\begin{array}{l}\text { The conclusions represent some kind of } \\
\text { tools for solving some particular problem, } \\
\text { but the generalization of solution could be } \\
\text { difficult. }\end{array}$ \\
\hline 4 & $\begin{array}{l}\text { Ideas are connected by the original } \\
\text { description of basic concepts with the } \\
\text { solver's assumption. }\end{array}$ & $\begin{array}{c}\text { The solution is created by useful information } \\
\text { from relevant sources, but some of them } \\
\text { negatively interfere with the main idea. }\end{array}$ & $\begin{array}{l}\text { The conclusions represent an important } \\
\text { tool for solving the equivalent problem, } \\
\text { for the problem with similar context or the } \\
\text { close discipline. It is possible to make with } \\
\text { modifications the universal conclusion. }\end{array}$ \\
\hline 5 & $\begin{array}{l}\text { Ideas are connected and combined mostly } \\
\text { in the original ways. Ideas create a complex } \\
\text { contribution for solving the problem. }\end{array}$ & $\begin{array}{l}\text { The solution is created mostly by correct } \\
\text { information. The inexact information or the } \\
\text { missing details do not have an influence on } \\
\text { the main idea. }\end{array}$ & $\begin{array}{l}\text { The conclusions represent a universal tool } \\
\text { for solving the problem with the same or } \\
\text { similar context or the close discipline. }\end{array}$ \\
\hline 6 & $\begin{array}{l}\text { Ideas are combined in an original and } \\
\text { surprising way for solving the problem or } \\
\text { creating of something new. The conception } \\
\text { of assignment is original. }\end{array}$ & $\begin{array}{l}\text { The solution is created by correct } \\
\text { information. }\end{array}$ & $\begin{array}{l}\text { The conclusions represent a universal tool } \\
\text { for solving problems from more disciplines. }\end{array}$ \\
\hline
\end{tabular}

Table 3: Set of rubrics to assess creativity (source: Bulková, Čeretková, 2017c) 


\begin{tabular}{l|l|c|l} 
& \multicolumn{1}{c}{ Assessed attribute } & $\begin{array}{c}\text { Levels } \\
\text { (min - } \text { max) }\end{array}$ & Name of variable \\
\hline Basic assignment (Subtasks 1a $-8 \mathrm{~b})$ & Mathematical competencies & $1-6$ & MathCom \\
\hline Final assignment (FA) & IBL competencies & $1-6$ & FA_IBL \\
\hline
\end{tabular}

Table 4: Names of didactical variables defined for parts of the assignment

\begin{tabular}{|c|c|c|c|}
\hline Assessed attribute & Criterion of assessed attribute & $\begin{array}{c}\text { Levels } \\
\text { (min - max) }\end{array}$ & Name of variable \\
\hline \multirow{3}{*}{ Mathematical Writing } & Integrity of mathematical text & $1-6$ & MWrit_Intg \\
\hline & Mathematical reasoning & $1-6$ & MWrit_Reas \\
\hline & Clarity and Readability & $1-6$ & MWrit_Clar \\
\hline \multirow{3}{*}{ Creativity } & Originality & $1-6$ & Cre_Orig \\
\hline & Correctness of conclusions & $1-6$ & Cre_CConcl \\
\hline & Applicability of conclusions and solving process value for following studies & $1-6$ & Cre_App \\
\hline
\end{tabular}

Table 5: Names of didactical variables defined for the criteria of assessed attributes

\section{RESULTS}

Out of total 29 submitted students' solutions, 21 started to solve the final assignment. The results obtained from the Cochran's $Q$ test $(Q(24)=232.396 ; p<0.001)$ imply that the three problems were not equally demanding (Table 6). The introductory tasks 1a and $1 \mathrm{~b}$ seem to be the least demanding, thus, students should apply the rule for given value of $a$ and number of hours $n$. The subtasks $7 \mathrm{a}$ and $7 \mathrm{~b}$ had the lowest/least success rate. The task $7 \mathrm{~b}$ is an investigation of the rule $x \rightarrow a x$ for the different values of $a$ and $n$. Students were asked to produce an original work, to find the number of loops as a function of $a$ and $n$, while in the task $7 \mathrm{~b}$ students should explain the rule constructed in the subtask $7 \mathrm{a}$. Further, we focus on some pseudo-implications where a subtask and the final assignment were present simultaneously. Out of all the pseudo-implications with the cohesion higher than 0.9 only the variables of the subtasks $2 a, 2 b, 4 d$ and $4 \mathrm{e}$ occurred together with any variable related to the final assignment. The subtask $2 \mathrm{a}$ was a reasoning task, while in the task $2 \mathrm{~b}$ students were expected to compose a congruence equation for the given rule, describe the way how they came to it and solved it in the end. The task 4 was focused on the target points of arrows. The subtask $4 \mathrm{~d}$ asked students to find a rule for finding a starting point of the target point for the given rule and $n$. This rule should have been adjusted and written as an equation for other $n$ in the 4e subtask.

The most significant (cohesion 0.991) pseudo-implication of this kind was the pseudo-implication $4 \mathrm{e}$ Cre Concl2 $\rightarrow$ FA MWrit_Clar2, it means that students who achieved the level $\overline{2}$ in the criterion for creativity "correctness of conclusions" in the subtask $4 \mathrm{e}$ were assessed at least by 2 in the criterion "clarity and readability" of mathematical writing. It means that the teams of students who were not able to formulate an appropriate reasoning for the subtask $4 \mathrm{e}$ did not write their solution of the final assignment very clearly.

The pseudo-implication 4e_Cre_Orig2 $\rightarrow$ FA_Cre_App2 (cohesion 0.988) indicates that the relatively low level of originality in the subtask $4 \mathrm{e}$ implies the low level of applicability of conclusions and problem solving processes in the final assignment. It means that students who were not able to formulate particular general pseudo-implications algebraically had real problems with some possible generalisations of the pseudo-implications in the final assignment. This pseudo-implication further implies the pseudo-implication 4e_Cre_Concl2 $\rightarrow$ FA_MWrit_Clar2 with cohesion 0.982 . This relation may indicate that the aspects of mathematical creativity can be related and therefore can influence different aspects of the solution of the final assignment.

Respective relations between creativity and other attributes of the solution can be seen in the R-rules for creativity in the subtasks $2 \mathrm{a}, 2 \mathrm{~b}, 4 \mathrm{~d}$ and $4 \mathrm{e}$. Correct solutions of these four tasks were significantly conditional only upon the variables describing different creativity criteria. There were not any more pseudoimplications implying the variables $2 \mathrm{a}$ CCor and $2 \mathrm{~b}$ Cor with cohesion higher than 80 (Figure 3).

\begin{tabular}{|c|c|c|}
\hline \multirow{2}{*}{ Task } & \multicolumn{2}{|l|}{ Success rate } \\
\hline & Frequency of correct solution & Group \\
\hline Task 1a & $96.6 \%$ & a \\
\hline Task 1b & $93.1 \%$ & ab \\
\hline Task 3b & $89.7 \%$ & $a b c$ \\
\hline Task 4b & $86.2 \%$ & abcd \\
\hline Task 3a & $86.2 \%$ & $\mathrm{abcd}$ \\
\hline Task 2b & $86.2 \%$ & abcd \\
\hline Task 2a & $86.2 \%$ & abcd \\
\hline Task 3c & $82.8 \%$ & abcde \\
\hline Task 1c & $79.3 \%$ & abcdef \\
\hline Task 4c & $69.0 \%$ & abcdef \\
\hline Task 4a & $62.1 \%$ & abcdefg \\
\hline Task 4d & $55.2 \%$ & bcdefgh \\
\hline Task $4 \mathrm{f}$ & $51.7 \%$ & cdefgh \\
\hline Task 1d & $51.7 \%$ & cdefgh \\
\hline Task 6a & $48.3 \%$ & defghi \\
\hline Task 8a & $41.4 \%$ & efghi \\
\hline Task 6b & $41.4 \%$ & efghi \\
\hline Task 4e & $37.9 \%$ & fghi \\
\hline Task 8b & $31.0 \%$ & fghi \\
\hline Task 6c & $31.0 \%$ & fghi \\
\hline Task 8c & $24.1 \%$ & ghi \\
\hline Task 6d & $24.1 \%$ & ghi \\
\hline Task 4g & $20.7 \%$ & ghi \\
\hline Task 7a & $17.2 \%$ & hi \\
\hline Task 7b & $10.3 \%$ & $i$ \\
\hline
\end{tabular}

Differences - frequencies followed by the same letter in column are not significantly different based on McNemar test ( $p \leq 0.05$ )

Table 6: Success rate in subtasks 


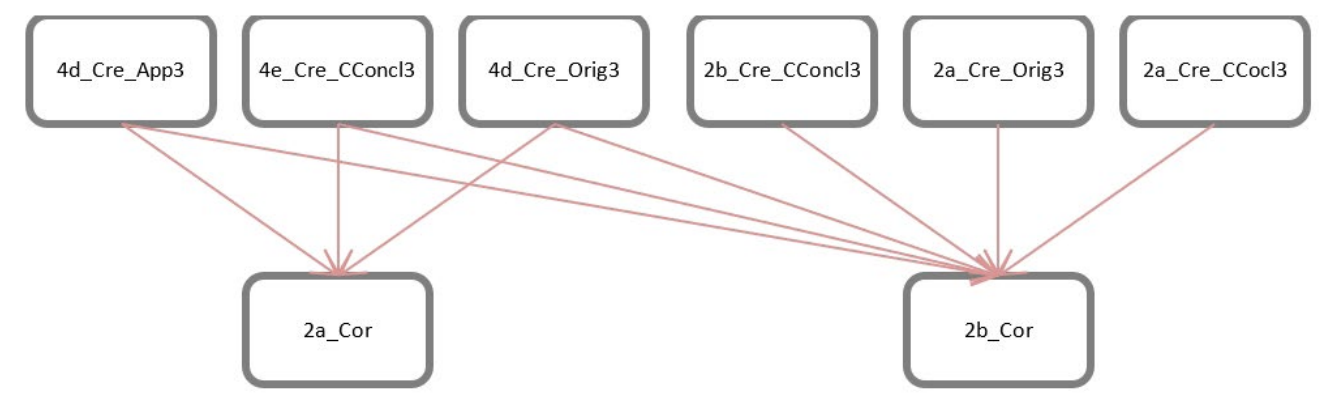

Red full arrow: Cohesion of the R-rule is higher than 99

Figure 3: R-rules including correctness of the subtasks $2 \mathrm{a}$ and $\mathbf{2 b}$

The previous pseudo-implication implies from FA IBL3, i.e. FA_IBL3 $\rightarrow((4 \mathrm{e}$-Cre_Origt2 $\rightarrow$ FA_Cre_App2) $\rightarrow$ $(4 \mathrm{e}$ Cre_CConcl2 $\rightarrow$ FA_MWrit_Clar2). Based on this it can be concluded that the pseudo-implication described is valid for such teams of students who used at least the level 3 IBL processes, e.g. discovering some connections and relationships, simplifying and structuring. The students who used the level 3 IBL processes fulfil at least the level 2 of creativity criteria. Thus, discovering some connections and simplifying is necessary for solving the $4 \mathrm{e}$ subtask and the final assignment manifesting criteria for creativity at the level 2 or higher. This implication partially confirms that the B-day assignment can be used for assessing these processes. It can be presumed that for solving the subtask $4 \mathrm{e}$ at a higher level, definitely, some higher IBL processes were necessary and needed.

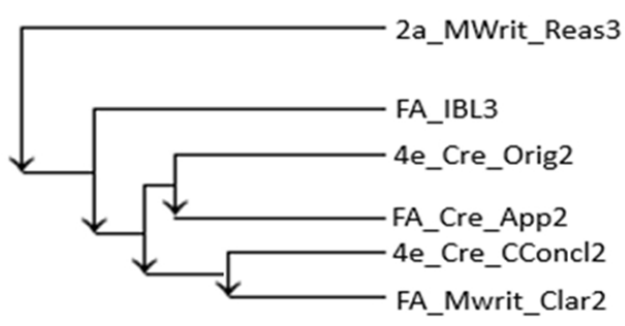

Figure 4: R-rules including correctness of the subtasks $2 a$ and $2 b$

The consecutive pseudo-implication 2a_MWrit_Reas3 $\rightarrow$ $\left(\right.$ FA_IBL3 $\rightarrow\left(\left(4 \mathrm{e}+C r e \_O r i g 2 \rightarrow\right.\right.$ FA_Cre_App2 $) \rightarrow(4 \mathrm{e}$ Cre_CConcl2 $\rightarrow$ FA_MWrit_Clar2)) with cohesion 0.934 (Figure 4) includes also the subtask 2a. The main aim of this subtask was to demonstrate the understanding of the representation in a form of modular equation. A new type of equation provides participating students with the algebraic tool for solving the problem. Relatively high level of reasoning in this subtask may imply that the students accommodated the algebraic generalisation and this allowed them to solve the complex further on a more general level.

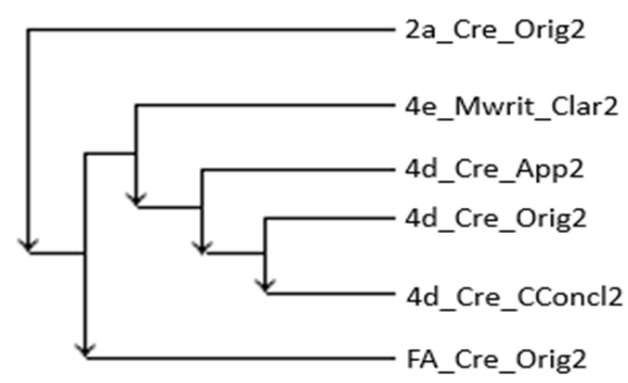

Figure 5: R-rules including correctness of the subtasks $2 a$ and $2 b$

Certain interrelations and importance of the all aspects of the creativity are confirmed also by following the pseudoimplications (Figure 5). The pseudo-implication 4d_Cre App2 $\rightarrow$ (4d_Cre_Orig2 $\rightarrow$ 4d_Cre_CConcl2) relates to the same level of the three investigated aspects of creativity manifested in one subtask, even though the manifested levels were relatively low. This relation is inferred by the low clarity of mathematical writing in the generalisation of the subtask 4e. Based on the pseudo-implication 4e_MWrit_Clar2 $\rightarrow$ $(4 \mathrm{~d}$-Cre_App2 $\rightarrow(4 \mathrm{~d}$ _Cre_Orig2 $\rightarrow$ 4d_Cre_CConcl2 $))) \rightarrow$ FA_Cre_Orig2) we may conclude that the overall low level of creativity manifested in the subtask $4 \mathrm{~d}$ and the low clarity of mathematical writing in the subtask $4 \mathrm{e}$ resulted in the low level of originality in the final assignment. The relations are further pseudo-implied by an insufficient reasoning in the subtask $2 \mathrm{a}$, as $2 \mathrm{a}$ Cre_Orig2 $\rightarrow((4 \mathrm{e}$ _MWrit_Clar2 $\rightarrow(4 \mathrm{~d}$ Cre_App $2 \rightarrow$ $(4 \mathrm{~d}$-Cre_Orig2 $\rightarrow$ 4d_Cre_CConcl2)) $\rightarrow$ FA_Cre_Orig2) (cohesion $c=0.926$ ).

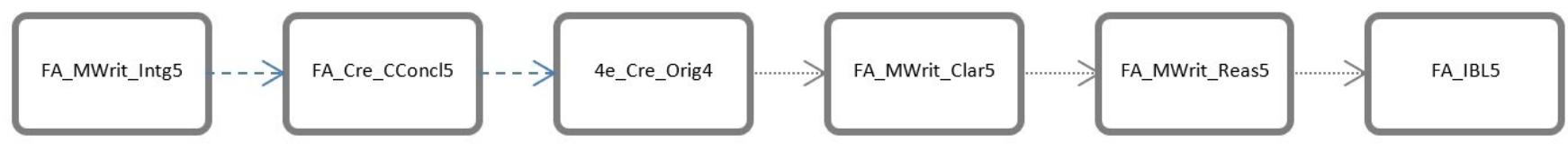

Blue dashed arrow: Cohesion of the R-rule is higher than 95; Grey dotted arrow: Cohesion of the R-rule is higher than 90

Figure 6: R-rules leading to the high level of manifested IBL competencies in the final assignment 
The processes of inquiry based learning are also present in a series of R-rules (Figure 6) leading to the variable FA IBL_5 which means that experimenting and inferring appear in the final assignment. It is conditioned by the high levels of integrity and clarity of mathematical writing, ability to formulate correct conclusions and provide reasoning in the final assignment and relatively high level of originality in the subtask $4 \mathrm{e}$ solution, i.e. with an ability to connect own ideas with the mathematical concepts provided in the assignment.

Students' solutions of the four subtasks were selected as an illustration of the coding (see Table 8). Solutions were distinguished by different ways of approaches.

\section{Example of the subtasks $2 a$ and $2 b$ from the assignment and authentic students' solutions}

'You looked into the rule of the form $x \rightarrow x+b$ for whole numbers $b$. In this case of an equilateral triangle we see: $x \rightarrow$ $x+b \rightarrow x+2 b \rightarrow x+3 b$. For these values of you will have an equilateral triangle... except for 0 .

2a Why do we also find $b=0$, while we do not get a triangle?' Arrow clocks (2017: 6)

\section{Solution A}

The parameter $\mathrm{b}$ determines, how we assign the point to given $\mathrm{x}$. In other words, if $b=4$ then the arrow will lead to such a point which is on the circle further by 4 units. If $b=0$, it means, the arrow will lead to a point plus 0 further. If the arrow leads to a point, which is by 0 further, it means, that the arrow leads to the same point, where we are now. In this case, there arises a loop.

So, we connect point 0 again with 0 , point 1 with 1 , point 2 with 2,3 with $3, \ldots$ and 12 with 12 . And therefore, if every point is connected within itself, it is not possible to arise any triangle between such points.

\section{Solution B}

If we have a general variable $n$ and we are trying to find the equilateral triangle for a random $b$, then $x \rightarrow x+b \rightarrow x+2 b \rightarrow$ $x+3 b$. Then it applies:

$$
\begin{gathered}
x \bmod n=(x+3 b) \bmod n \\
x \bmod n=x \bmod n+3 b \bmod n \\
0=3 b \bmod n
\end{gathered}
$$

It results from the above given that $3 b=n k+0$, where $\mathrm{k}$ is the integer. After dividing by 3 , we get $b=n k / 3$. If $n=12$, we get $b=4 k$ and it means, that $\mathrm{b}$ is the multiple of number 4. Except for $b=0$ there is no triangle, because $x$ appears in $x$, and all three vertexes of the triangle will be identical. In case of the subtask $2 \mathrm{a}$, students were encouraged to explain the specific situation for $x \rightarrow x+b$, where $b=0$. Both solutions achieved the different level of mathematical competencies. Thus, in Solution A, students described the above-mentioned situation from more dependent reports and very clearly and the text is composed of more dependent reports, however, it is just a processed information from the assignment slightly complemented by symbolic and formal operations. Even the conclusion of the solution is correct, it is not formulated for the next applicability and it is not supported by mathematical argumentation. On the other hand, the comparison with Solution B shows an evident difference in the level of manifested mathematical competencies. Thus, students in Solution B described the solution also by a mathematical object and relation, in the concrete by modular arithmetic. Relatively high level of writing skills is represented by students' reasoning. The final report contains a mathematical argumentation needed for processing the mathematical text. Even the final idea of the solution is right, the correctness is interfered by the usage of the incorrect symbols for relation of congruence modulo $n$. The representation is expressed as the equation $(=)$ except for the relation of the congruence $(\equiv)$. In final, the conclusion with small corrections is applicable as a tool for solving the same or close problems.

' $2 \mathrm{~b} \quad$ You can investigate in the same way for what $b$ the rule $x \rightarrow x+b$ leads to the equilateral pentagons on a 15 hours' clock. Provide the equation; explain how you found it; and show you can solve it.' Arrow clocks (2017: 6)

\section{Solution A}

This relation expresses the all values $b$, by which the regular pentagon is created on the 15 -hours dial. We put together the equation based on experimenting in GeoGebra. We found the values $b$, with which the regular pentagon is created and we found out there is a sequence between them. Based on this sequence $(3,12,18, \ldots)$, we created the abovementioned relation. For every $k$, there are two values of $b$, which exist by adding or subtracting of number 3 .

\section{Solution B}

$x+5 b \equiv x(\bmod 12)$, because for arising the pentagon, we need to move $x$ five times by number $\mathrm{b}$, so that the point can return back to the initial $x$. Since $x<15$, so $x(\bmod 15)=x$, and we can write the equation in this way:

$$
\begin{gathered}
x+5 b(\bmod 15)=x \\
5 b(\bmod 15)=0 \\
5 b=15 k, k \in Z \\
b=3 k
\end{gathered}
$$

If this equation holds, so for the given $b$ we get the pentagon. Especially values for $b: b \in\{3 ; 6 ; 9 ; 12\}$. For the value 3 we get the convex regular pentagon and for value 6 we get the regular five-point star, which vertexes lying on the circumcircle may be considered for vertexes of the regular convex pentagon, but in the same time, five new points arise by intersecting the line segments, which are connecting the points on the circumcircle. If the pentagon is considered as a unit, which points are lying on the circumcircle, so the solution is also number 6 , if we look on the unit like on the decagon, so the number 6 is not any solution. Number 12 gives the same pattern as number 3 .

For what reason are only these two numbers the solution? We can exclude all shifts by $b$, from which we can reach to the same point for the same $x$ (the resultant patterns will be the same), so in the solution it is enough to state only $b_{1} \in\left\{b_{1} ; b_{2} ; \ldots\right\}$, for its elements $b_{n}$ and $b_{m}$ holds: 


$$
\begin{gathered}
x+b_{n} \equiv x+b_{m}(\bmod 15) \\
b_{n} \equiv b_{m}(\bmod 15) \\
b_{n}=b_{m}+15 k, \quad k \in Z
\end{gathered}
$$

The subtask $2 \mathrm{~b}$ followed after the subtask $2 \mathrm{a}$, where the dial was extended from $n=12$ to $n=15$. Students in Solution A reached the conclusion based on the experimenting in GeoGebra. The conclusion of the solution is not formulated for the next applicability and it is not supported by a mathematical argumentation. The solution is composed only of the written description deducted from the assignment. Therefore, the conclusion does not represent a tool for solving the problem, even for other purposes. Solution B represents the coherent mathematical text supported by the mathematical argumentation. The conclusion represents the tool useful for solving the equivalent problem or for a problem with a similar context. It is necessary to point out, that students in Solution B distinguished the standard equation and relation of congruency.

\section{Example of the subtasks $2 a$ and $2 b$ from the assignment and authentic students' solutions}

'For the rule $x \rightarrow 4 x$ and $n=15,1$ is a target point, because $4 \rightarrow 1$.

4d Use the fact that $4 \rightarrow 1$ to quickly find the starting point of the arrows with target points $2,3,4, \ldots, 14$.' Arrow clocks (2017: 8).

\section{Solution A}

The formula $x \rightarrow 4 x$ for $n=15$ has its target point 1 , because $4 \rightarrow 1$ to quickly find the starting points for arrows with target points $2,3,4, \ldots, 14$. Whereas we know the target points, we can find out starting points for whatever arrow thanks to approach in part c). Then, for example, number 2 :

$$
\begin{gathered}
4 x=2(\bmod 15) \\
4 * 8=32(\bmod 15)=2(\bmod 15)
\end{gathered}
$$

The starting point of the arrow, which leads into number 2 is 8 . For other numbers, we have these below given starting points (see Table 7).

\begin{tabular}{lcccccccccccccc}
\hline Target points & 2 & 3 & 4 & 5 & 6 & 7 & 8 & 9 & 10 & 11 & 12 & 13 & 14 & 15 \\
\hline Starting points & 8 & 12 & 1 & 5 & 9 & 13 & 2 & 6 & 10 & 14 & 3 & 7 & 11 & 15 \\
\hline
\end{tabular}

Table 7: Solution A for the subtask 4d

\section{Solution B}

The finding, that $4 \rightarrow 1$, we can use to quickly find starting points for the arrows with target points $2,3,4, \ldots, 14$. If $x \rightarrow$ $4 x$ holds, then:

$$
\begin{gathered}
4 x \equiv \bmod (15)=15 k+y \\
4 x=15 k+y \\
4 x-15 k=y \\
x=\frac{y+15 k}{4}
\end{gathered}
$$

The number $k$ has to be as small as it is possible to get to the point y after the first turn. We substitute for $k$ gradually 0 as first, then 1,2 , until we find $\mathrm{k}$ so, that $y+15 k$ was divisible by 4. Then we will find also $x$.

The assignment was aimed at looking for patterns which were created by formulas of the functions. However, in the subtask $4 \mathrm{~d}$, students were asked to find the formula based on one representation. Both examples of students' solutions are described by mathematical objects and relations significant between them. In Solution A, students used the formula from the previous subtask. Though, the equation is not clearly stated in the description of the subtasks solution. The selected approach contains the required elements for solving some partial problems, but not for the entire problem as a whole. The solution is tabular. The argumentation and reasoning skills were at a higher level in Solution B. The conclusion in solution represents a universal tool for solving the problem with the same or similar context or a close discipline.

' $4 \mathrm{e} \quad$ Use the same method to indicate with an equation what the starting point is for every target point 1 , $2,3, \ldots, 44$ for $x \rightarrow 4 x$ and $n=45$.' Arrow clocks (2017: 8).

\section{Solution A}

By the same method, we would like to find out the starting point also for the all target points, if $x=4 x$ for $n=45$. We already know, that $34 \rightarrow 1$, because $34 * 4=136 \equiv 1(\bmod 45)$. Thus, if $a$ is the target point, then we can calculate its starting point as $34 a(\bmod 45)$. This is because each following starting point (for the next target point) is by 34 distanced from the previous one.

\section{Solution B}

Now we have values $x \rightarrow 4 x$ and $n=45$. Let's divide the values of target points into 4 groups: $4 p, 4 p+1,4 p+2,4 p+3$, where $p$ is the integer. With these values $k=\{0,3,2,1\}$, where we can express the formulas for $x$ :

$$
\begin{array}{ll}
y=4 p: & 4 p=4 x-0 * 45, x=p \\
y=4 p+1: & 4 p+1=4 x-3 * 45, x=p+31 \\
y=4 p+2: & 4 p+2=4 x-2 * 45, x=p+23 \\
y=4 p+3: & 4 p+3=4 x-1 * 45, x=p+12
\end{array}
$$

From this we are able to calculate every $\mathrm{x}$ if we know $\mathrm{y}$, where $p=\left[\frac{y}{4}\right]$.

The subtask $4 \mathrm{e}$ was solved only by a few teams. The usage of the knowledge of concepts, facts, assertions and approaches were observable in Solution A. But the application of symbolic, formal and technical operations was missing in the written solution as well as a deeper argumentation. The solution so can be unclear in some parts. Solution B represents mathematical text which is supported by mathematical argumentation, even the details connecting it with the assignment were not explained. For this reason, even the solution contains some useful information, where some of it interferes with the correctness of the solution negatively. 


\begin{tabular}{c|c|c|c|c|c|c|c} 
& MathCom & MWrit_Intg & MWrit_Reas & MWrit_Clar & Cre_Orig & Cre_CConcl & Cre_App \\
\hline $2 \mathrm{a}$ & 1 & 3 & 1 & 4 & 2 & 5 & 1 \\
\hline $2 \mathrm{~b}$ & 3 & 4 & 4 & 4 & 3 & 4 & 5 \\
\hline $4 \mathrm{~d}$ & 2 & 2 & 2 & 3 & 3 & 4 & 2 \\
\hline $4 \mathrm{e}$ & 5 & 4 & 5 & 4 & 4 & 4 & 5 \\
\hline
\end{tabular}

Table 8: Coding based on the rubrics

The subtask 4e was really demanding for the all students. After excluding variables connected to the final assignment, one of the most significant pseudo-implications (cohesion 0.962) was 4e_Cor $\rightarrow$ (4e_MathCom4 $\rightarrow$ (4e_MWrit_Intg5 $\rightarrow\left(4 \mathrm{e} \_\right.$MWrit_App5 $\leftrightarrow$ 4e_MWrit_Clar4)) )). The aspects as integrity, reasoning and clarity are difficult to be assessed separately, whereas, they are closely inter-related. The subtask $4 \mathrm{e}$ was solved correctly only by such teams who were able to reason at the high levels, their mathematical writing is clear and their resulting coherent text almost without any errors. The correct solution of this task is not related to the fact whether the students attempted to solve the final assignment or not (MannWhitney's U test, $p=0.521$ ). However, on the other hand, the levels of almost all other studied variables (except aspects of originality, $p=0.052$ ) of the final assignment differ significantly according to the Mann-Whitney's U test based on the correct solution of the task $4 \mathrm{e}$ (Figure 7). In contrary, however, the other three subtasks present in pseudo-implications with the high cohesion $(2 \mathrm{a}, 2 \mathrm{~b}, 4 \mathrm{~d})$ were not in a significant relation to any of the described variables.

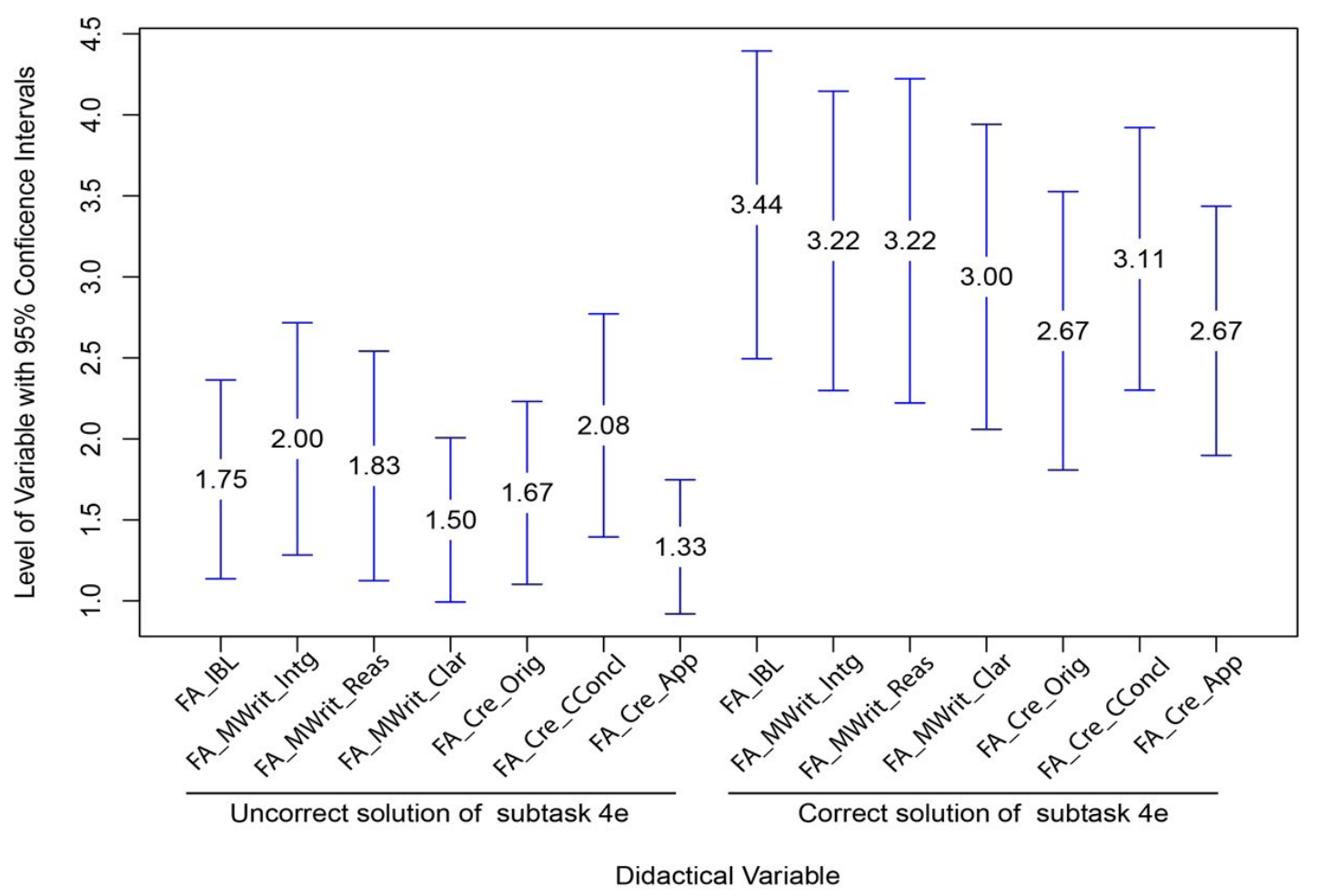

Figure 7: Plot means of variables describing the final assignment grouped by correctness of the solution of the $4 \mathrm{e}$ subtask

The statistical implicative analysis allowed us to define the 4 subtasks related to different aspects of students' solutions of the final assignments. Admittedly, success in solution of the subtasks $2 \mathrm{a}$ and $2 \mathrm{~b}$ was mainly influenced by different attributes of mathematical creativity demonstrated in various subtasks (including 4d and 4e).

The correct solution of the subtask $4 \mathrm{e}$, where some teams of students should compose the general equation, seemed to be crucial for the high level of the solution of the final assignment and hence for success in the competition. On the other hand, the solution of subtask $2 b$ in the form of equation was necessary for general investigations in final assignment and did not influence the levels of different aspects of the final assignment. In contrast with the subtask $2 \mathrm{~b}$, the desired equation in subtask $4 \mathrm{e}$ was not necessary for the success in final assignment.

\section{DISCUSSION}

The main objective of this paper was to identify crucial processes, steps and skills necessary and required in solving complex mathematical problems. To observe high-level competencies used within the mathematical inquiry we worked with a problem stated for the mathematical contest and its solution by highachieving upper-secondary students.

We are aware that our study has several limitations. Firstly, we focused only on some high-achieving students able to investigate mathematically and create innovative conclusions. However, exactly the focus on their high ability allowed us to observe a relationship between the basic and the final assignment.

It is necessary to point out that the final reports were composed by selected teams of students. In relation to this, Stacey (1992) found that teams' solution was not necessarily better than 
individual one. Even though some groups have sufficient amount of ideas they fail to select the correct ones.

Based on the results implied from the statistical implicative analysis we identified the partial problems (subtasks) related to the final assignment which require an original mathematical investigation. The subtasks $2 \mathrm{a}, 2 \mathrm{~b}, 4 \mathrm{~d}$ and $4 \mathrm{e}$ were related to the final assignment. Two of these ( $2 a$ and $2 b$ ) were conditional only upon the variables describing different creativity criteria. It is in accordance with Dow and Mayer (2004: 389) who found that 'solutions to mathematical insight problems lie in a novel approach to numbers'. These results confirm also the findings of Kamp (2016: 30) who claims that '...creativity in mathematics by the attitude to solving process is represented. Any solver focused on more possibilities to solve a given problem is open to reach a new view on the world, not only on mathematics'.

The subtask $4 \mathrm{e}$ requires students to develop an equation. Pantziara, Gagatsis and Elia (2009: 55) state that 'for novel tasks, like non-routine problems whose abstract structures are not known, the form of representation can determine the information that can be perceived, the processes that can be activated, and the structures that can be uncovered from the specific representation.' Generalising a pattern algebraically does rest in the capability of grasping commonality of particulars, extending it to the all subsequent terms and being able to provide a direct expression. According to Radford (2008: 95), students often fail at working out a formulation of the direct and meaningful rule, and only some students with their well-developed algebraic thinking are able to work with expressions and equations where signs and numbers 'acquire a non-contextual, relational mode of signification'.

\section{CONCLUSIONS}

This study was carried out with the aim to shed some light on the low-investigated area of solving novel complex problems. Within the basic assignment, we tried to identify some subtasks necessary for the successful solution of the final assignment by means of the statistical implicative analysis. The four subtasks were confirmed as having the greatest impact. The two subtasks ( $2 \mathrm{a}$ and $4 \mathrm{~d}$ ) were aimed at facilitating students to get a deeper insight to the problem situation and consecutive subtasks ( $2 \mathrm{~b}$ and $4 \mathrm{e}$ ) ask students to provide an outcome in the form of an equation.

The correct solution of the subtask $4 \mathrm{e}$ can be used as a predictor of the high-level performance in the final assignment despite an algebraic expression was not required there. Nevertheless, the necessary algebraic expression obtained in the subtask $2 \mathrm{~b}$ did not show this effect. It seems that not the content but the processes involved in finding out for a solution are the actual key to the good performance in the field of mathematical investigation, particularly, in our Mathematics B-day contest.

Certainly, the well-developed, established and rooted social competencies of students (as mutual interaction and communication) are needed to be observed for the complex assessment of teamwork on mathematical open-ended problems requiring the inquiring in mathematics.

\section{ACKNOWLEDGEMENT}

This work was supported by the Slovak Research and Development Agency under the contract No. APVV-150368 and by the University Grant Agency of Constantine the Philosopher University in Nitra under the contract no CGA VII/3/2019.

\section{REFERENCES}

Anderson, L. W., Krathwohl, D. R. (eds.) (2001) A Taxonomy for Learning, Teaching and Assessing: A revision of Bloom's Taxonomy of Educational Objectives: Complete edition. New York : Longman.

Arrow clocks (2017) Mathematics B-day 2017 assignment [Online] Available: http://www.fisme.science.uu.nl/wisbdag/opdrachten/ assignment2017.pdf [2 Apr 2018].

Blaško, M. (2013) Kvalita v systéme modernej výučby. [The quality in system of modern education] Košice: Technical University in Košice.

Bloom, B. S., Engelhart, M. D., Furst, E. J., Hill, W. H. and Krathwohl, D. R. (1956) Taxonomy of educational objectives. The Classification of Educational Goals. Michigan: Edward Bros.

Brookhart, S. M. (2013) How to Create and Use Rubrics for Formative Assessment and Grading. Alexandria, VA: Association For Supervision \& Curriculum Development.

Bruder, R., Prescott, A. (2013) 'Research evidence on the benefits of IBL', ZDM Mathematics Education, vol. 45, pp. 811-822. https:// doi.org/10.1007/s11858-013-0542-2

Bulková, K., Čeretková, S. (2017a) 'Rubrics as assessment tool of mathematical open-ended problems', APLIMAT 2017: Proceedings from 16th Conference on Applied Mathematics, Bratislava, Bratislava: STU, pp. 235-245.
Bulková, K., Čeretková, S. (2017b) 'Písomný prejav žiakov v riešeniach otvorených matematických problémov’, Študentská vedecká konferencia 2017: zbornik recenzovaných prispevkov z konferencie, Nitra: UKF, pp. 458 - 463.

Bulková, K., Čeretková, S. (2017c) 'Creativity as assessed attribute in mathematical open ended problém solving', EDULEARN17: Proceeding from 9th International Conference on Education and New Learning Technologies, Barcelona: IATED, pp. 583 - 590. https://doi.org/10.21125/edulearn.2017

Couturier, R. (2008) 'CHIC: Cohesive Hierarchical Implicative Classification ', in Gras, R., Suzuki, E., Guillet, F. and Spagnolo, F. (ed.) Statistical Implicative Analysis, vol. 127, pp. 41-53. https://doi.org/10.1007/978-3-540-78983-3 2

Dorier, J. L. (2012) Context analysis for the implementation of IBL: International synthesis report, [Online] Available: http:// www.scientix.eu/resources/details?resourceId=4039 [15 Jan 2015]

Dow, G. T. and Mayer, R. E. (2004) 'Teaching students to solve insight problems: Evidence for domain specificity in creativity training', Creativity Research Journal, vol. 16, no. 4, pp. 389-398. https:// doi.org/10.1080/10400410409534550

Ďuriš, V. and Lengyelfalusy, T. (2019) Notes on Discrete Mathematics, Karlsruhe: Ste-Con, 
Engeln, K., Euler, M., and Maass, K. (2013) 'Inquiry-based learning in mathematics and science: A comparative baseline study of teachers' beliefs and practices across 12 European countries', ZDM, vol. 45, pp. 823-836. https://doi.org/10.1007/s11858-013$\underline{0507-5}$

Gonda, D. and Tirpakova, A. (2018) 'A new teaching method aimed at eliminating the causes of students'unsuccessful algorithmic problem solving with parameter'. Problems of education in the 21st century, vol. 76, no. 4, pp. 499-519.

Gras, R., Almouloud, S. A., Bailleul, M., Lahrer, A., Polo, M., Ratsimba-Rajohn, H., Totohasina, A. (1996) L'implication statistique: nouvelle méthode exploratoire de données, applications à la didactique. [Statistical implicative analysis: new exploratory method of data, applications to didactics: La Pensée sauvage]. La Pensée sauvage.

Kamp, A (2016) Engineering Education in the Rapidly Changing World. Rethinking the Vision for Higher Engineering Education. $2^{\text {nd }}$ Edition. Delft: TU Delft.

Kenderov, P. S. (2006) 'Competitions and Mathematical Education', International Congres of Mathematicians: Proceedings, vol 3. https://doi.org/10.1007/978-3-319-62597-3

Kosko, K. W. and Wilkins, J. L. M. (2010) 'Mathematical Communication and Its Relation to the Frequency of Manipulative Use', International Electronic Journal of Mathematics Education, vol. 5, no. 2, pp. 79-90.

Leikin, R. and Pitta-Pantazi, D. (2013) 'Creativity and mathematics education: the state of the art', ZDM Mathematics education, vol. 45. pp. 159-166. https://doi.org/10.1007/s11858-012-0459-1

Lock, R. (1990) 'Open- ended, problem-solving investigations. What do we mean and how can we use them?', School Science Review, vol. 71, no. 256, pp. 63-72.

Maaß, K. and Artigue, M. (2013) 'Implementation of Inquiry-based learning in day-to-day teaching: A synthesis', ZDM Mathematics Education, vol. 45, no. 6. pp 779-795. https://doi.org/10.1007/ s11858-013-0528-0

Maaß, K. and Reitz-Koncebovski, K. (eds.) (2013) Inquiry-based learning in maths and science classes. What it is and how it works - examples - experiences, [Online], Freiburg: Pädagogische Hochschule Freiburg, Available: http://primas-project.eu/ wpcontent/uploads/sites/323/2017/11/primas final_publication. pdf [10 May 2019]

Medová, J., Bulková, K. and Čeretková, S. (2018) 'Identification of crucial competencies in mathematical inquiry', ERIE 2018: Proceedings of the $15^{\text {th }}$ International Conference, Prague: Czech University of Life Sciences, pp. 203-212.

Moskal, B. M. (2000) 'Scoring Rubrics: What, when and why?', Practical Assessment, Research and Education, vol. 7, no. 3.
Nesher, P., Hershkovitz, S. and Novotna, J. (2003) 'Situation model, Text Base and what else? Factors affecting Problem Solving', Educational Studies in Mathematics, vol. 52, pp. 151-176. https://doi.org/10.1023/A:1024028430965

Nohda, N. (2000) 'Teaching by Open-Approach Method in Japanese Mathematics Classroom', Proceedings of the Conference of the International Group for the Psychology of Mathematics Education. Japan. vol. 1, pp. 39-53.

Pantziara, M., Gagatsis, A. and Elia, I. (2009) 'Using diagrams as tools for the solution of non-routine mathematical problems', Educational Studies in Mathematics, vol 72, pp. 39-60. https:// doi.org/10.1007/s10649-009-9181-5

$\mathrm{R}$ Core Team (2018) R: A Language and Environment for Statistical Computing. Vienna: R Foundation for Statistical Computing.

Radford, L. (2008) 'Iconicity and contraction: a semiotic investigation of forms of algebraic generalizations of patterns in different contexts', ZDM Mathematics Education, vol. 40, pp. 83-96. https://doi.org/10.1007/s11858-007-0061-0

Russek, B. (1998) 'Writing to Learn Mathematics', Writing Across the Curriculum, vol. 9, pp. 36 - 45.

Samková, L. (2018) 'Uplatnění otevřeného přístupu k matematice v prrípravě kudoucích učitelů 1 . stupně ZŠ - Empirická studie $\mathrm{v}$ kontextu badatelsky orientovaného kurzu [Employing an Open Approach go Mathematics in Pre-Service Primary School Teacher Training - An Empirical Study in the Context of an Inquiry-Based Course]', Studia paedagogica, vol. 23, no. 3, pp. 49 - 67. https://doi.org/10.5817/SP2018-3-3

Schoenfeld, A. H. (1992) 'Learning to think mathematically: problem solving, metacognition, and sense making in mathematics' in Grous, D. (ed.) Handbook for Reasearch on Mathematics Teaching and Learning. New Yourk: Macmillan.

Stacey, K. (1992) 'Mathematical problem solving in groups: Are two heads better than one?', Journal of Mathematical behaviour, vol. 11, no. 3, pp. 261-275.

Sternberg, R. J. (ed.) (1998) Handbook of Creativity. Cambridge: Cambridge University Press. https://doi.org/10.1017/ CBO9780511807916

Utrecht University (2018) Mathematics B-day. [Online] Available: https://www.uu.nl/en/education/mathematics-b-day [1 Mar 2018]

Yackel, E. and Rasmussen, C. (2002) 'Beliefs and norms in the mathematics classroom' in Leder, G. C. (ed) Beliefs: A hidden variable in mathematics education?, pp. 313-330, Dordrecht: Kluwer Academic Publisher. https://doi.org/10.1007/0-306$\underline{47958-3 \quad 18}$

Zak, P. (2004) Kreativita a její rozvoj. [Creativity and its development]. Brno: Computer Press.

\section{APPENDIX}

The subtasks $2 \mathrm{a}$ and $2 \mathrm{~b}$ from assignment Arrow clocks (2017).

You looked into the rule of the form $x \rightarrow x+b$ for the whole numbers $b$. In the case of an equilateral triangle, we see: $x \rightarrow x+b \rightarrow x+2 b \rightarrow x+3 b \ldots$ For these values of $b$ you will have an equilateral triangle... except for 0 .

2a Why do we also find $b=0$, while we do not get a triangle?

$2 \mathrm{~b} \quad$ You can investigate in the same way for what $b$ the rule $x \rightarrow x+b$ leads to the equilateral pentagons on a 15 hours' clock. Provide the equation; explain how you found it; and show you can solve it.

The subtasks $4 \mathrm{~d}$ and $4 \mathrm{e}$ from assignment Arrow clocks.

$4 d \quad$ Use the fact that $4 \rightarrow 1$ to quickly find the starting point of the arrows with target points $2,3,4, \ldots, 14$.

$4 \mathrm{e} \quad$ Use the same method to indicate with an equation what the starting point is for every target point $1,2,3, \ldots, 44$ for $x \rightarrow 4 x$ and $n=45$. 